BANCA D'ITALIA

E U R O S I S T E M A

Questioni di Economia e Finanza

(Occasional Papers)

Housing rent dynamics in Italy

by Concetta Rondinelli.and Giovanni F. Veronese 

13 BANCA D'ITALIA

E U ROS I S T E MA

\section{Questioni di Economia e Finanza}

(Occasional papers)

Housing rent dynamics in Italy

by Concetta Rondinelli and Giovanni F. Veronese

Numero 62 - February 2010 
The series Occasional Papers presents studies and documents on issues pertaining to the institutional tasks of the Bank of Italy and the Eurosystem. The Occasional Papers appear alongside the Working Papers series which are specifically aimed at providing original contributions to economic research.

The Occasional Papers include studies conducted within the Bank of Italy, sometimes in cooperation with the Eurosystem or other institutions. The views expressed in the studies are those of the authors and do not involve the responsibility of the institutions to which they belong.

The series is available online at www.bancaditalia.it. 


\title{
HOUSING RENT DYNAMICS IN ITALY
}

\author{
by Concetta Rondinelli and Giovanni F. Veronese*
}

\begin{abstract}
In this paper we focus on tenant rents in Italy and compare results from several methods for the rent dynamic estimation. We first document the sources of data available and then introduce quality-adjusted techniques, which enable us to separate the price variation due to qualitative changes in housing attributes from pure price changes. Finally, we compare these measures with unconditional and matched-type price indices derived from microdata. Over the period 1998-2006, we estimate a cumulative rent increase ranging between 40 and $80 \%$. The upper bound refers to the average dynamic for a subset of flats entering the market in a given period. The hedonic approach suggests a substantially lower overall growth in tenant rent, around $40 \%$ for the same period.
\end{abstract}

JEL Classification: C21; C43; C81; E31; R21.

Keywords: Hedonic regressions, matched-models, CPI, downward bias

\section{Contents}

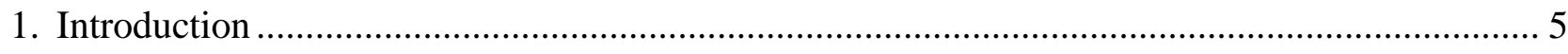

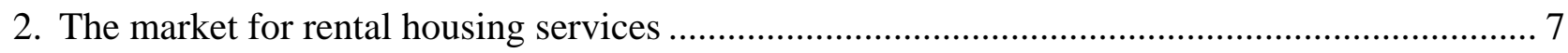

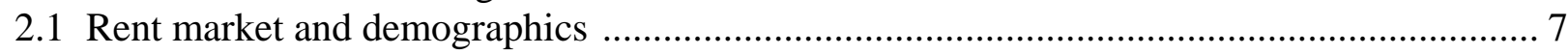

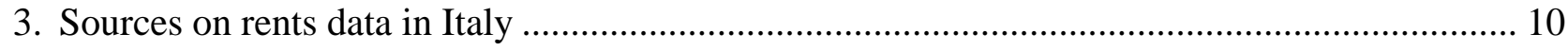

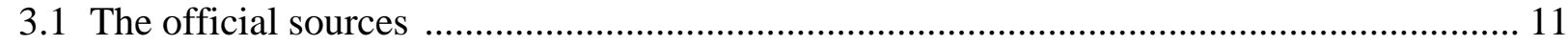

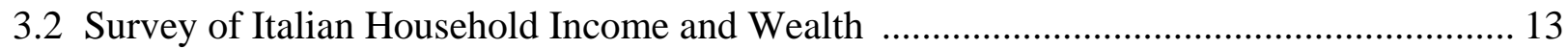

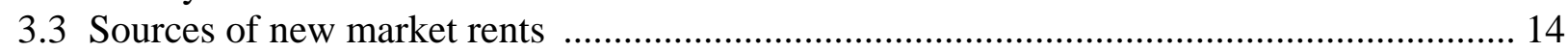

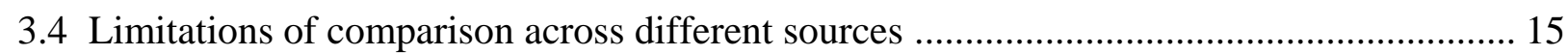

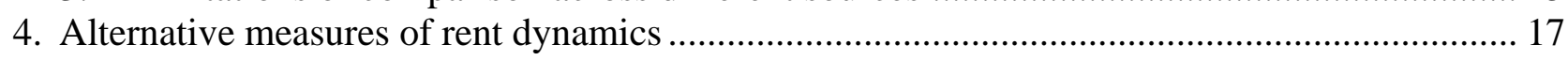

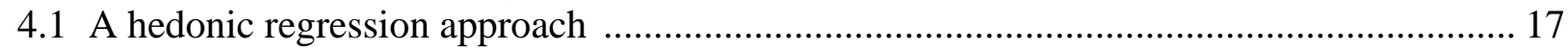

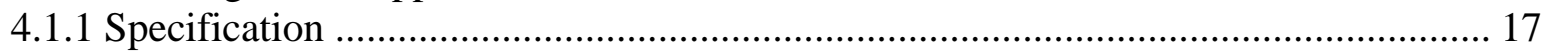

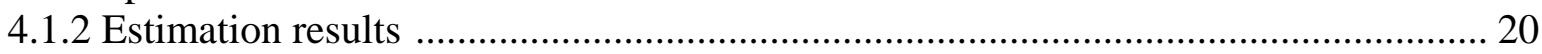

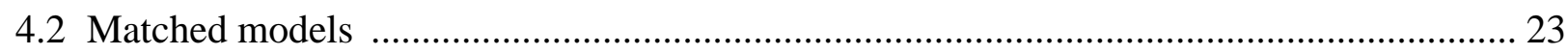

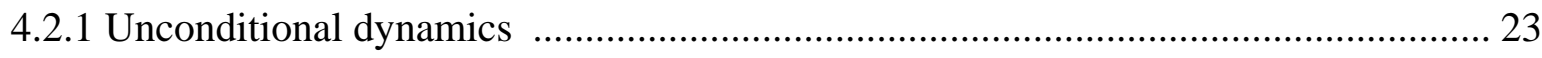

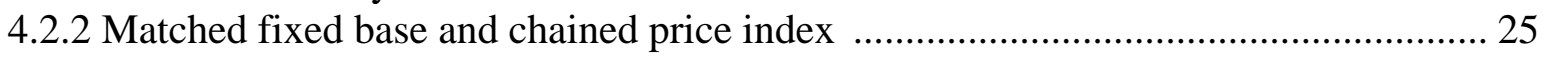

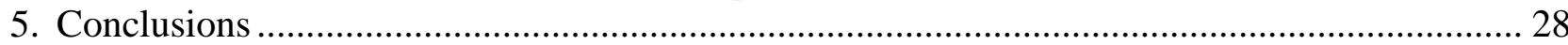

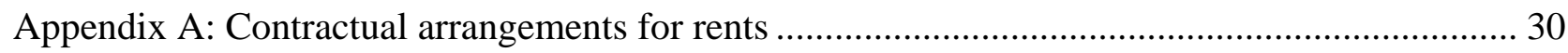

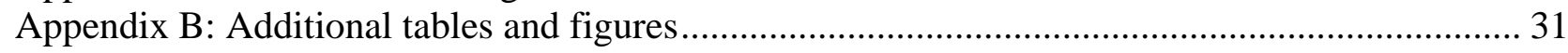

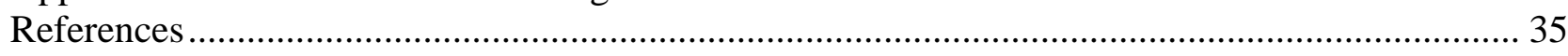

* Bank of Italy, Economic Outlook and Monetary Policy Department. 



\section{Introduction}

Developments in the housing market have become an increasingly important element in the information set monitored by Central Banks. One of the lessons of the recent global crisis was that excessive asset price inflation, originating in the financial and in the real estate sector, needs to be kept under constant scrutiny for its potential disruptive impact on financial stability. As to the real estate market, in order to gauge the extent of misalignment of prices from fundamentals, good quality statistics on prices as well as on returns (i.e. rents) are essential (see the discussion by Visco to Goodhart, 2005). In the euro area availability of statistics on house prices and on rents varies significantly across countries. The Bank of Italy has recently started a survey of the housing market (Panetta et al., 2009) while Eurostat is considering the inclusion of house prices into the Harmonized Index of Consumer Prices (HICP) to cover the owner occupied component.

Dynamics in house prices and rental costs have also significant distributional implications. The cost of housing (for owners and occupiers) is one of the key sources of heterogeneity in consumption patterns across segments of the population, impacting particularly on lower income and younger households. Sharp increases in housing costs are found to lead to a postponement of youth emancipation decisions (Haurin et al. 1993, Ermisch, 1999 and Becker et al. 2005), to discourage labor mobility choices (Bentolila and Dolado, 1991 and Cannari et al., 1997) and to reduce the total fertility rate (Kohler et al. 2002). Duce Tello (1995) suggests that young Italians are increasingly late in leaving the parental home, possibly due to lack of financial resources or affordable housing. In this respect, since these transitions generally involve renting an apartment, rents dynamics may be a more relevant variable than house prices.

Empirical analysis on rent dynamics are still rather scant for the euro area, mainly because of a lack of data. An exception is Germany, where Hoffmann and Kurz (2002), exploiting household survey data use hedonic methods to construct an indicator of rent inflation. Their findings suggest the existence of a slight downward bias in the rents subindex of the German CPI in the early 1990s. Similar analysis performed for the US (Gordon and vanGoethem, 2005, and Crone et al., 2006) reveals a downward bias of the CPI rent subindex of approximately 0.5-1 per cent annually.

In this paper we resort to a suite of statistical techniques to measure tenant rent dynamics in Italy. To tackle the data problem in the Italian 
context we first assemble a unique database on rental levels. We resort to multiple sources of data available from various agencies, based both on household surveys, where rents are reported by the tenant, as well as on private real-estate agency listings in the largest municipalities.

To analyze rent dynamics we follow three strategies. We compute qualityadjusted price indices for rents from the household survey datasets using standard hedonic methods, as in Hoffman and Kurz (2002). We then compare these statistics with those obtained by estimating average national rents per square meter from the various sources. In this case several steps of aggregation are used, which depend on the type of data. With household survey data we compute average rents using the corresponding survey sampling weights; with rental listings data we instead aggregate rents at the city level using weights computed from the Bank of Italy Survey on Household Income and Wealth (SHIW), as well as population weights. Finally, we exploit the panel dimension of the household survey (SHIW) to construct matched-type price indices where price increases are computed over stable apartment units.

Mirroring the sharp increase in house prices over the period 1998-2006 (about $60 \%$ in Panetta et al., 2009), according to our calculations tenant rents increased substantially, with estimates ranging widely, between 40 and $80 \%$ in cumulative terms, depending on the reference source and the method used. Not surprisingly, the largest growth rate is recorded by those measures which rely on data from rent listings, reflecting presumably the changing composition of vacant apartments on the market. The estimates from household surveys, both using the hedonic approach and the matched-type methods, suggest instead a substantially lower overall growth in tenant rents, around $50 \%$ between 1998 and 2006. In the same period, according to the key official measure of rents dynamics available, i.e. the "tenants rents" component of the Consumer Price Index (CPI), the increase amounted to 20\%, less than half than our most conservative calculations.

The paper is organized as follows. Section 2 identifies a class of households for which rent plays a central role, while Section 3 provides a brief description of the Italian data sources currently available for studying rent dynamics. We then report quality-adjusted indices, based on hedonic methods in Section 4.1 and compile indices of apartment rents based on both simple statistical measures and matched model indices in Section 4.2. Section 5 concludes. 


\section{The market for rental housing services}

In recent years several demographic factors have determined an increasing pressure on the housing market: the gradual reduction in average household size, the increase in immigration flows and the coming of age of a larger share of the population. Using the SHIW survey for the last thirty years, Gambacorta and D'Alessio (2007) construct housing affordability indices (both for house ownership and rental) which show a marked increase in the financial burden of housing for Italian households. They also point to the potential for a severe exacerbation of such a burden following an increase either in interest rates or in house prices.

In the decade 1991-2001 the Italian population increased by only $0.4 \%$, while the number of households rose by $8.8 \%$ (Census data); between 2001 and 2006 the population rose by $3.7 \%$, while the number of households increased by $11.2 \%$. In the same period immigration accounted for almost 2 percentage points of overall population growth. ${ }^{1}$ Finally, the share of the population in the 30-39 age group, which corresponds to the typical emancipation age in the last decade, recorded a significant increase, reaching a peak in 2004 (at 16.2\%), only slowly declining thereafter.

On the supply side the Italian housing stock increased by $1.7 \%$ a year in the period 2000-2006; the growth was greater in the North, with an increase of about $12 \%$, at an average rate of $2 \%$ a year, and in the Center (see Figure $1)$; it was more subdued in the South (1.2\% per annum).

These factors contributed to an increasing housing shortage, especially of the cheapest kind, more marked in the last decade, with many observers (see Osservatorio regionale sulla condizione abitativa, 2008) pointing to the need of larger investments in social-housing projects. Public investment in housing (both partially and fully funded) declined steadily in the period 1985-2004, from more than 50,000 houses per year to approximately 10,000 (Cresme, 2005).

\subsection{Rent market and demographics}

The Italian rental housing market is considerably smaller than in the rest of the euro area. In 2002 about $20 \%$ of Italian households lived in a rented

\footnotetext{
${ }^{1}$ It should be noted however that due to the regularizations in 2002-2003 of migrants already in Italy, the contribution of immigration flows to overall population growth may refer to a longer time span.
} 
Figure 1: The Italian housing stock

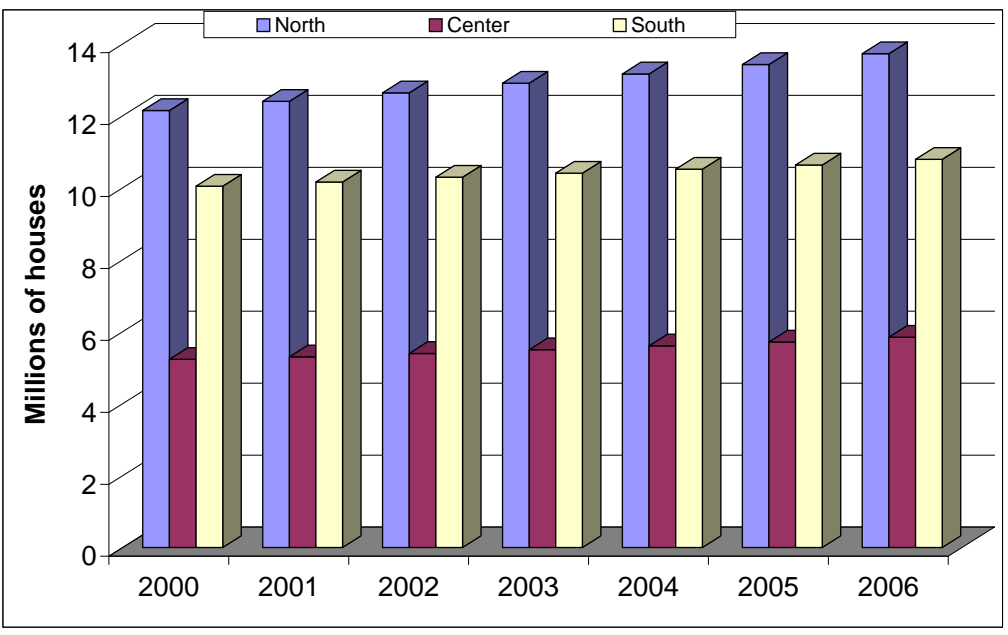

Source: Rapporto Immobiliare (2007), Osservatorio mercato immobiliare dell'Agenzia del Territorio

dwelling compared to nearly $60 \%$ in Germany and $45 \%$ in France (OECD, 2005). Furthermore, rents accounted for approximately $1.9 \%$ of Italian households' expenditure, compared to $7.2 \%$ in Germany and $4.3 \%$ in France. This difference is reflected in the weight of rental services in the Harmonized Index of Consumer Prices (HICP) basket in Italy, which ranks among the lowest in the euro area (see Table 1).

Table 1: The weight (\%o) of rental housing in the HICP

\begin{tabular}{c|cccccccccccc} 
& EM & DE & FR & IT & ES & BE & NL & AT & PT & FI & GR & LU \\
\hline 2001 & 65.8 & 111.1 & 63.8 & 28.2 & 21.3 & 64.3 & 97.8 & 36.4 & 16.2 & 51.8 & 36.7 & 45.6 \\
2002 & 65.0 & 110.8 & 61.8 & 27.1 & 21.6 & 64.2 & 95.5 & 36.2 & 15.6 & 75.7 & 31.2 & 39.3 \\
2003 & 64.0 & 111.1 & 63.8 & 28.2 & 20.7 & 65.0 & 72.1 & 37.1 & 20.0 & 76.4 & 31.8 & 37.1 \\
2004 & 64.0 & 110.8 & 65.7 & 28.3 & 22.6 & 64.0 & 73.3 & 36.7 & 20.0 & 77.2 & 32.3 & 35.7 \\
2005 & 63.5 & 109.4 & 66.2 & 27.5 & 22.9 & 63.9 & 74.6 & 39.4 & 20.2 & 79.2 & 33.0 & 34.6 \\
2006 & 63.2 & 108.2 & 66.5 & 28.1 & 23.3 & 64.3 & 76.5 & 36.8 & 20.2 & 85.2 & 33.1 & 34.6 \\
2007 & 62.1 & 107.8 & 67.8 & 22.4 & 23.3 & 64.2 & 76.8 & 37.1 & 20.4 & 86.0 & 29.1 & 33.4 \\
\hline
\end{tabular}

Source: Eurostat.

According to the SHIW, the proportion of owner occupiers remained farly stable in the '90s (77\%), increasing to $80 \%$ in 2000 . In 2006 the share of 
families renting their house (excluding "riscatto" and "usufrutto" contracts ${ }^{2}$ ) amounted to $20 \%$ (see Table 11 in Appendix B). This share displays substantial heterogeneity according to the demographic characteristics of the households and their economic status: home ownership increases with the age of the head of the household, peaking in the over-65 age group ( $84 \%$ in 2006); in contrast, younger households rent their homes (around $41 \%$ in 2006 when the age of the head of the household is below 30 years). Unsurprisingly, home ownership increases with income: more than $90 \%$ of the wealthiest households own their house, only $58 \%$ when considering the first quartile of the household income distribution. Within the lowest quartile approximately $78 \%$ are households whose head is either older than 65 or younger than 30; however, a clear divide in terms of house property emerges between these age segments: $65 \%$ of young low income households rent their house while $71 \%$ of the older ones own their principal residence (see Table 2).

The financial burden of renting the house is greater for low income households: as shown in Figure 2 for these households rent expenditure accounts for about $20 \%$ of household revenue; almost $14 \%$ for families with disposable annual income above 25,000 euros (approximately the $75^{\text {th }}$ percentile of the distribution in 2006). At the bottom of the distribution a relevant fraction of households still pay a very low rent compared to their overall consumption expenditure (a small hump on the left of the curve): this reflects the fact that a large number of rental contracts of the "equo-canone" kind are still in place (see Appendix A). The first quartile of the income distribution reveals a large variation and a clear divide between young (right hump shape) and old (left) households.

Home ownership is strictly related to the working status of the head of the household: self-employed individuals are more likely to own their house (81.2\% in 2006) when compared with employees (73.9\%). This difference is further amplified when considering the sub-group of households with a single earner, as shown in Table 3. As pointed out by Boeri and Brandolini (2005), during the period 1993-2002 Italian income distribution has remained stable because of significant distributive changes across socio-economic groups to the advantage of households of self-employees.

\footnotetext{
${ }^{2}$ In this paper we will assume that "market contracts" include "patti in deroga" and "uso foresteria/ufficio" while "subsidized contracts" include "equocanone", "informale/amichevole", "case popolari", "canone sociale".
} 
Table 2: Lower income households: home tenure by age

\begin{tabular}{|c|c|c|c|c|c|c|c|c|c|c|}
\hline \multicolumn{2}{|l|}{ Age } & 1991 & 1993 & 1995 & 1998 & 2000 & 2002 & 2004 & 2006 & Total \\
\hline \multirow[t]{2}{*}{ up to 30 years } & ownership & 37.5 & 47.2 & 46.1 & 42.6 & 48.2 & 46.2 & 34.4 & 34.9 & 42.0 \\
\hline & rent & 62.5 & 52.8 & 53.9 & 57.4 & 51.8 & 53.8 & 65.6 & 65.1 & 58.0 \\
\hline \multirow[t]{2}{*}{31 to 40} & ownership & 46.1 & 45.0 & 51.7 & 49.3 & 40.1 & 49.6 & 37.3 & 39.0 & 44.9 \\
\hline & rent & 53.9 & 55.0 & 48.3 & 50.7 & 59.9 & 50.4 & 62.7 & 61.0 & 55.1 \\
\hline \multirow[t]{2}{*}{41 to 50} & ownership & 45.5 & 53.6 & 49.1 & 47.7 & 56.0 & 47.6 & 47.2 & 44.3 & 49.1 \\
\hline & rent & 54.5 & 46.4 & 50.9 & 52.3 & 44.0 & 52.4 & 52.8 & 55.7 & 50.9 \\
\hline \multirow[t]{2}{*}{ over 65} & ownership & 72.7 & 64.9 & 68.4 & 72.1 & 77.5 & 74.8 & 75.6 & 71.4 & 72.2 \\
\hline & rent & 27.3 & 35.1 & 31.6 & 27.9 & 22.5 & 25.2 & 24.4 & 28.6 & 27.8 \\
\hline & Total & 64.6 & 60.6 & 62.5 & 63.4 & 68.0 & 64.2 & 61.3 & 58.1 & 62.9 \\
\hline & & 35.4 & 39.4 & 37.5 & 36.6 & 32.0 & 35.8 & 38.7 & 41.9 & 37.1 \\
\hline
\end{tabular}

Source: Our calculation from the SHIW. Percentage points. Lower income households are defined as those receiving an income smaller than the 25 th percentile of the income distribution.

Not surprisingly, home ownership increases with the household size. Finally, it is more frequent in the South than in the North, and it is less common in large than in small towns (70\% in 2006 against $85.1 \%$ ).

Table 3: Single earner households: home tenure by occupation

\begin{tabular}{|r|rcccccccc|}
\hline \multicolumn{1}{l|}{} & & $\mathbf{1 9 9 1}$ & $\mathbf{1 9 9 3}$ & $\mathbf{1 9 9 5}$ & $\mathbf{1 9 9 8}$ & $\mathbf{2 0 0 0}$ & $\mathbf{2 0 0 2}$ & $\mathbf{2 0 0 4}$ & $\mathbf{2 0 0 6}$ \\
\hline employee & ownership & 0.53 & 0.70 & 0.61 & 0.66 & 0.57 & 0.54 & 0.56 & 0.53 \\
& rent & 0.47 & 0.30 & 0.39 & 0.34 & 0.44 & 0.46 & 0.44 & 0.47 \\
\hline self-employed & ownership & 0.65 & 0.59 & 0.70 & 0.68 & 0.73 & 0.74 & 0.67 & 0.74 \\
& rent & 0.35 & 0.41 & 0.30 & 0.32 & 0.28 & 0.26 & 0.33 & 0.26 \\
\hline not employed & ownership & 0.75 & 0.71 & 0.73 & 0.77 & 0.83 & 0.81 & 0.83 & 0.81 \\
& rent & 0.25 & 0.29 & 0.27 & 0.23 & 0.17 & 0.19 & 0.17 & 0.19 \\
\hline
\end{tabular}

Source: Our calculation from the SHIW. Percentage points. Individual characteristics refer to the household head.

\section{Sources on rents data in Italy}

The main Italian source on rent dynamics is the CPI rent subindex compiled by the National Institute of Statistics (ISTAT). Being a price index, it does not provide any information on the underlying levels. Furthermore, ISTAT releases other rental measures in the context of the national accounts, household consumption survey and general census (see Section 3.1).

Information on tenant rents is also available either from periodic surveys of households or from price surveys run by national associations of estate 
Figure 2: Share of income devoted to rent expenditure by quartile

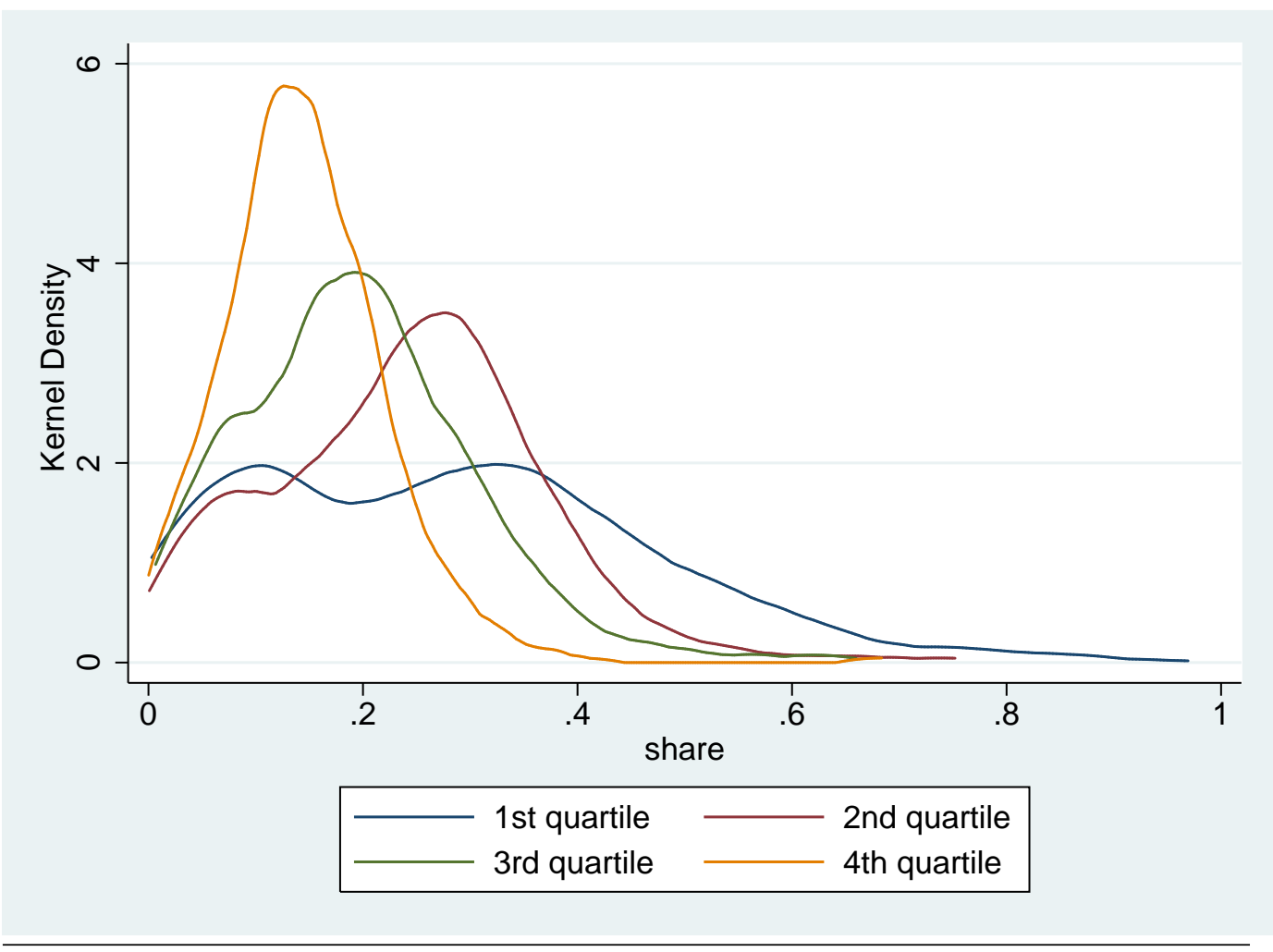

Source: Our calculation from SHIW, 2006

agents. While the former reports the amount paid by interviewed tenants to rent the dwelling, the latter typically refers to the market rent for vacant apartments (Section 3.2 and 3.3). In addition to the rent level, household surveys contain questions related to the tenant as well as to the dwelling characteristics: a list of the variables and sources exploited in this paper is given in Table 10.

\subsection{The official sources}

ISTAT collects and publishes data on rents and housing conditions within the following context:

- the Consumer Price Index (CPI); 
- the National Accounts (CNA);

- the Household Consumption Expenditure budget survey (HCS);

- the General Census of Population and Housing (Census).

As to the CPI, rent price indices are calculated on the basis of a sample of apartments: the data collection is conducted quarterly in the provincial capitals, where the survey is also designed. ${ }^{3}$ Unlike most observations collected in the CPI survey which are posted prices, those for rents are measured using transaction prices as reported by tenant interviews. A municipal commission establishes annually a target sample of houses and apartments composed of approximately 10,000 apartments nationwide. The CPI index is a Laspeyres type indicator which means that weights refer to a base period and that the sample refers to apartments that were already rented in the base period and ISTAT follows their evolution over time. The continuity of sampled apartments is insured by their substitution with other dwellings with similar characteristics in terms of neighbors' status, location, size, house ownership, etc. As a consequence, in a given year the CPI rent index monitors the evolution of both existing contracts, typically indexed to a percentage of the headline inflation, and renewed one; the former being more frequently included in the sample because of the nature of Laspeyres index. For this reason we expect the CPI index represents a lower bound for our estimates.

The national account rent deflator (CNA) is available yearly and it is calculated from the HCS data by directly computing the ratio of current rent expenditure to a base period one. It is estimated classifying apartment prices into 42 standard types, defined from the house characteristics available in the HCS. As depicted in Figure 3, over the period 1998-2006 the CPI and CNA rent index show a different pattern pointing to a cumulative rent increase of about $20 \%$ and $50 \%$ respectively, mainly because of the methodology of data collection and sample design.

Information on rents is also collected by ISTAT from the HCS annual survey which constitutes the key input in the estimates of consumption expenditure for the national accounts. The HCS survey provides information on the patterns and the level of consumption of Italian households residing in Italy, according to various demographic and social characteristics. It is conducted annually in nearly 500 municipalities including approximately 28,000

\footnotetext{
${ }^{3} \mathrm{An}$ exhaustive written manual on the CPI price collection is available online from the ISTAT website.
} 
Figure 3: CPI rent price index and national account rent deflator $(1998=100)$

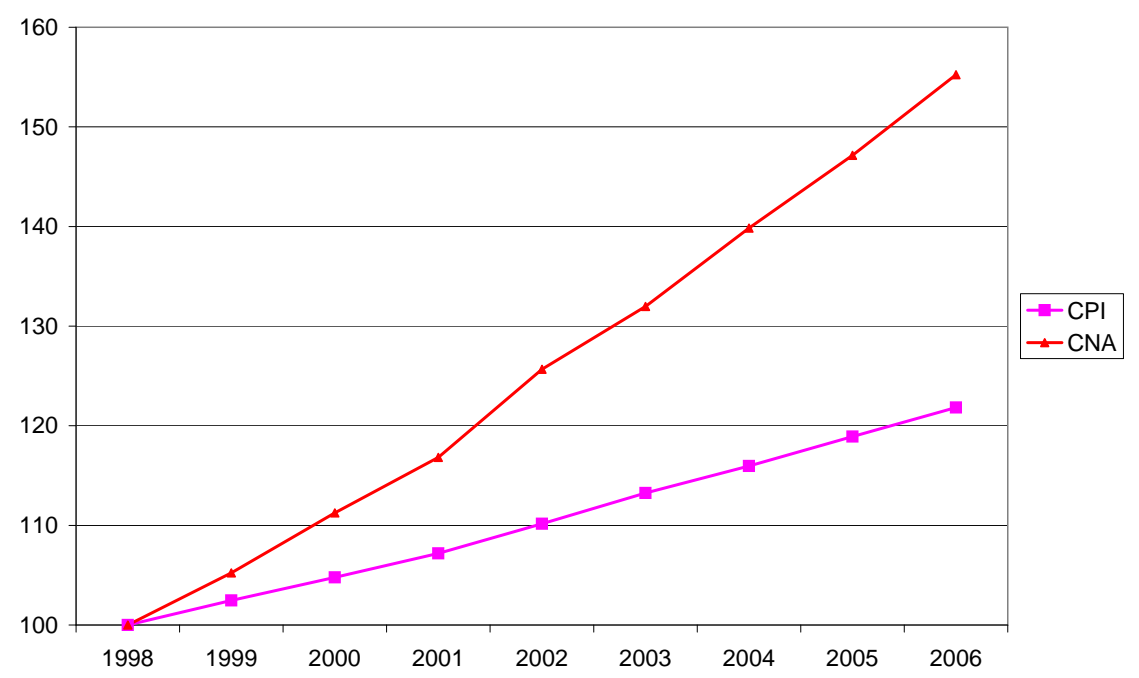

Source: ISTAT.

households, sampled at random from the residence records of the municipalities involved in the survey. The data is collected for 278 elementary consumption items, providing a very detailed picture of consumption patterns. Sampling weights allow to expand the sample to the whole population. Real consumption measures are mostly obtained by deflating elementary nominal consumption items with the corresponding price indices from the CPI.

The Census provides the most complete survey on the housing stock and on the rent/ownership situation. Despite being collected only once every ten years it is a useful source to complement the more frequent information available from other surveys. We resorted to the publicly available $1 \%$ random subsample of the Census data to impute, via matching methods, some variables on house characteristics which were missing from the HCS survey.

\subsection{Survey of Italian Household Income and Wealth}

The Bank of Italy Survey on Household Income and Wealth conducted every two years ${ }^{4}$, is the main source of information on Italian household savings

\footnotetext{
${ }^{4}$ An exception is 1998 , when there was a discontinuity of three years in the survey.
} 
and wealth. The 2006 sample comprises around 8,000 households drawn from the registry office records of 330 municipalities. Data are collected by means of professional interviews and are representative of the universe of Italian households. Under the SHIW sampling design, each household is assigned a weight inversely proportional to its probability of inclusion in the sample; the weights are subsequently modified to take account of non-response, to increase the precision of the estimators, and to align the structure of the sample with that of the population in terms of certain characteristics. ${ }^{5}$ The estimates of the value of housing stock obtained from SHIW for the subsample of the home owners are a key element in measuring Italian households' wealth (see Cannari and Faiella, 2008). In contrast, we focus on the subsample of households that rent their house, who are asked how much they pay, along with a variety of questions about their dwelling, such as location, surface area, presence of facilities, type of owner and type of the rent contract.

While the CPI sample is specifically designed to provide an accurate picture of the evolution of prices over time, the HCS and SHIW are instead cross-sections representative of the Italian population in each wave. In order to infer information regarding the evolution of rents over time we need to exploit more waves of these surveys and carefully control for the possible changes in the sample population. Furthermore, because both the HCS and SHIW are sampled at the household level, the estimated price measure in a given year can be considered as a mixture of new contracts (i.e. those households for which the survey year $y_{t}$ coincides with the year they become tenants $y_{r}$ ) and renewals (i.e. $y_{t}>y_{r}$ ).

\subsection{Sources of new market rents}

In a given period new market rent contracts are more likely to capture current market trends. Several sources of new rent contracts exist in Italy. We rely on the two most complete datasets. The first is "Il Consulente Immobiliare" (CI) semiannual survey conducted for a special review published by $I l$ Sole

\footnotetext{
${ }^{5}$ The sample for the survey is drawn in two stages (municipalities and households), with the stratification of the primary sampling units (municipalities) by region and demographic size. Within each stratum, the municipalities in which interviews are to be conducted are selected to include all those with a population of more than 40,000 inhabitants (self-representing municipalities), while the smaller towns are selected on the basis of probability proportional to size. The individual households to be interviewed are then selected randomly.
} 
24 Ore media group: along with new house prices it collects data on new contract rents for a very large sample of Italian municipalities. It was widely exploited to study house price developments (see Muzzicato et al. 2008, for a detailed description of the dataset), but never in great detail for rent prices. In each sampled town, CI provides estimates of the average rent level (per square meter) of an apartment located in three areas: center, semi-center and suburbs. Rents are further distinguished into new and renewed contracts, the latter defined as contracts negotiated with previously sitting tenants upon contract expiration.

Our second dataset is the "Osservatorio del mercato immobiliare" (OMI) managed by a public agency, the "Agenzia del Territorio". Since the second half of 2002 the OMI has collected semiannual data on a large number of housing units sold in all Italian municipalities, covering virtually the entire national housing market. The OMI data take the form of price estimates for a typical ${ }^{6}$ dwelling (per square meter): such estimates, provided as a minimum-maximum range, are available for extremely detailed town areas (also know as micro-zones). ${ }^{7}$ These price estimates are derived from local commissions that under the supervision of personnel from the OMI examine all sampled prices in a certain micro-zone. The sources for the elementary rent data are mainly real estate agencies and other experts opinions. In the most recent OMI surveys the micro information underlying house price estimates is also cross-checked with the notary registration mandatory for a newly purchased house. Unfortunately, such a validation is not feasible for rents as a large part of contracts go unrecorded.

Both CI and OMI record new rent contracts whose dynamics are expected to be more relevant for those individuals considering whether to change their residence. Furthermore, they may provide an upper bound for the rent dynamics recorded by other surveys.

\subsection{Limitations of comparison across different sources}

Despite this wealth of sources for rent data, several factors complicate the task of obtaining a truly representative sample to analyze rent dynamics over a sufficient time span.

Some of these factors are related to the nature of the available datasets.

\footnotetext{
'In terms of neighbors' status, location, size, etc.

${ }^{7}$ In 2006, for example in Rome about 400 micro-zones were selected.
} 
Unfortunately the time span and the data frequency are not the same across sources. In the next sections we will focus on annual data for the period 1998-2006: the SHIW figures for odd years are obtained by interpolating even years, while CI and OMI data are averages of semiannual ones. Additionally, OMI data are assumed equal to CI before 2002. For comparison reasons, when considering $\mathrm{CI}$ and $\mathrm{OMI}$ data we restrict the sample to the observations on the provincial capitals, while when using HCS and SHIW data we use the full sample, as only a regional breakdown is available in these datasets.

Other factors are connected with the large fraction of rent contracts that go unrecorded ${ }^{8}$ and with the problem of sample attrition and heterogeneous non-response biases from tenants. Furthermore, a correct measure of rent price variations is complicated by the issue of quality change in the sampled apartments: negative, due for example to house depreciation, and positive following, for example, maintenance work.

In order to analyze rent dynamics we estimate average national rents per square meter from the various surveys. The aggregation methods used depend on the type of data. With SHIW and HCS data we compute directly average rents per square meter using their sampling weights. In contrast, with OMI and CI data we first aggregate rents at the city level using weights computed from SHIW and then, using weights based on the population residing in each town, we obtain national averages.

The reader should be aware that a direct comparison between these statistical approaches is limited given that the methodology of data collection and sample design of the indicators are different. In particular, the CPI rent index is a chained Laspeyres index that uses base period quantities and it follows a pre-defined sample of flats. The divergence with indicators built on new rent contracts and with household survey based measures should then be interpreted with caution.

The remainder of this paper will propose a quality adjusted measure of rent indices based on hedonic methods which have been widely used in the studies related to high-tech products (Section 4.1). We will then look at the development of rents as described by simple statistical measures and matched-type indices (Sections 4.2.1 and 4.2.2).

\footnotetext{
${ }^{8}$ Some observers estimate that almost $50 \%$ of rented apartments are not declared for tax purposes (Secit, 2006).
} 


\section{Alternative measures of rent dynamics}

In this section we report indices of apartment rent compiled from different data sources; these indicators will contribute to a better understanding of rent dynamics in Italy. We resort to hedonic methods to estimate quality adjusted price increase for rents and compile rent indices based on both simple statistical measures and matched-model indices.

\subsection{A hedonic regression approach}

Quality adjusted methods are nowadays standard when analyzing markets characterized by a marked product differentiation (Griliches, 1971), or when technological innovation leads to a high product turnover rate.

The flow of services arising from the lease of an apartment depend on a rich bundle of house characteristics: location, size, age, number of rooms and other amenities. Therefore, measures of rent dynamics calculated from cross-sectional averages over time may confound actual price changes with variations in the average house traits.

On the other hand, comparing the prices of a fixed set of dwellings, thereby holding their characteristics constant (except of course for age), is potentially problematical as the survey sample may become less representative of the rental market. This situation is akin to the one arising when studying products exhibiting a high turnover rate, like high-tech goods. It is well known that in that case the left tail of the distribution of price changes is likely to be missed by standard price index methods, causing an upward bias in the estimated price dynamics. As to the latter, Pakes (2005) argues that "it is the great ability of hedonic indices to handle sample attrition that is the most important reason favoring hedonic prices". We believe a similar problem may arise in our context, although the censoring occurs at the upper tail of the distribution, as apartments experiencing contract renewals are more likely to fall outside the price surveyor sample.

\subsubsection{Specification}

We estimate hedonic regression on both the SHIW and the HCS samples, using similar specifications. The hedonic functions map characteristics of a differentiated good, in our case housing services, into a price with the 
following specification:

$$
p_{i t}=\gamma_{0}+\delta_{t}+\beta s_{i t}+\sum_{k=1}^{K} \alpha_{k, t} c_{i, k, t}+u_{i, t}
$$

where $p=\log (P)$ and $P$ is the rent of the dwelling, $s=\log (S)$ and $S$ is its size (in square meters), $c$ are a set of dummy variables for the presence of certain characteristics such as a private heating system or a garage, the location in the city, the district, etc, and subscripts $t$ and $i$ denote the period and the dwelling, respectively. The way the dependent variable is chosen depends on the price index, so that if the index is based on a geometric mean of prices we should use the logarithm of prices (see Reis and Santos Silva, 2006). The terms $\delta_{t}$ are time dummy coefficients defined as changes with respect to the base year intercept $\gamma_{0}$, so that $\delta_{t}=\sum_{\tau=1}^{T} d_{\tau, t}$, where $d_{\tau, t}$ takes the value 1 when $t=\tau$ and 0 otherwise. In total $(\mathrm{T}+1)$ periods are observed. By introducing a log-log specification in the dependent variable and in the apartment size we can estimate the price to size elasticity $\beta$. We also experiment with more flexible specifications, where this elasticity may vary with other house characteristics, but do not find any significant improvement in the fit. After a simple transformation, the time dummy variables in our specifications can be interpreted directly as changes in price with respect to the base period that are not due to changes in any of the other characteristics included in the equation. Hence, a rent price index can be recovered cumulating the estimated time dummies.

Hedonic regression models are usually estimated pooling data and using the traditional time dummy-variables method where the quality adjusted time index is estimated using the dummies period; this approach assumes coefficients are constant over the time horizon. A way to overcome this limitation is to use adjacent years in the estimation procedure imposing a dummy variable for one period only and allowing the coefficient to be stable over two consecutive years. Our sample involves a long time span, so that the stability of a single hedonic price function may be an unrealistic assumption as housing characteristics are likely to affect prices differently over time (Triplett, 2004). This hypothesis is indeed rejected by an overall stability test (see Table 4). We hence relax this assumption and estimate adjacent-period equations where the hedonic function is now required to be stable only across two adjacent survey years. A stability test for the coefficients estimated in two adjacent years does not reject the null at $1 \%$ level, 
for the $\alpha$ and $\beta$ coefficients in (1) starting from 2000. The instability of the coefficients over the years $1998 / 2000$ is mainly related to the introduction of the new currency in the euro area, while the discontinuity for the period $1995 / 1998$ is imputed to the survey characteristics. ${ }^{9}$

\section{Table 4: Robust Specification tests}

\begin{tabular}{|c|c|c|c|c|c|c|c|}
\hline Sample years & & $1995 / 06$ & $1995 / 98$ & $1998 / 00$ & $2000 / 02$ & $2002 / 04$ & $2004 / 06$ \\
\hline \multirow[t]{2}{*}{$\left.\operatorname{RESET}^{a}\right)$} & Test Statistics & 1.300 & 3.050 & 1.210 & 0.750 & 1.240 & 2.080 \\
\hline & $p$-value & 0.260 & 0.010 & 0.302 & 0.587 & 0.286 & 0.065 \\
\hline \multirow[t]{2}{*}{ Chow ${ }^{b)}$} & Test Statistics & 3.480 & 2.270 & 2.150 & 1.900 & 0.830 & 0.670 \\
\hline & $p$-value & 0.000 & 0.004 & 0.007 & 0.022 & 0.636 & 0.807 \\
\hline Number of Observations & & 10212 & 3569 & 3260 & 3343 & 3345 & 3300 \\
\hline Sample years & & 1995 & 1998 & 2000 & 2002 & 2004 & 2006 \\
\hline \multirow[t]{2}{*}{$\operatorname{RESET}^{a)}$} & Test Statistics & 3.46 & 0.45 & 2.13 & 0.75 & 9.66 & 1.13 \\
\hline & $p$-value & 0.004 & 0.811 & 0.059 & 0.584 & 0.00 & 0.342 \\
\hline Number of Observations & & 1986 & 1583 & 1677 & 1666 & 1679 & 1621 \\
\hline
\end{tabular}

Pakes (2003) suggests that both the assumption of stability in the coefficients over a long time horizon and over two years could be violated if the products are rapidly changing. In Table 5 we report the main characteristics of the units in the sample. Although dwelling characteristics are rather stable over time, we also estimate year-by-year regressions, but the results are not significantly different from those obtained pooling adjacent years. ${ }^{10}$

In the presence of so many explanatory variables it is easy to neglect important interactions or to specify inadequate transformations of the continuous variables. Adequate specification of the estimated functional form was tested using the heteroscedasticity robust RESET test. Except for the years $1995 / 1998$ (see footnote ${ }^{9}$ ) the test suggests there is no misspecification of the functional form when considering two adjacent years. Evidence of some misspecification of the hedonic function arises in the year-by-year regressions (see bottom panel of Table 4).

\footnotetext{
${ }^{9}$ In 1998 a new market research organization, Eurisko, substituted Doxa and data quality improved.

${ }^{10}$ Results are available upon request.
} 
To sum up hedonic regressions that use data on one year only are more likely to be misspecified, whereas there is no evidence of misspecification for the model estimated using two consecutive years. Henceforth our preferred quality-adjusted price index will be based on adjacent years.

\section{Table 5: Descriptive statistics of the Hedonic regression (shares)}

\begin{tabular}{lcc|cc|}
\cline { 2 - 5 } & \multicolumn{2}{c}{ SHIW } & \multicolumn{2}{c|}{ HCS } \\
\cline { 2 - 5 } & $\mathbf{1 9 9 8}$ & $\mathbf{2 0 0 6}$ & $\mathbf{1 9 9 8}$ & $\mathbf{2 0 0 6}$ \\
\hline Ownership of the household & & & & \\
Private Individuals & 0.7 & 0.7 & 0.69 & 0.71 \\
Private Company & 0.05 & 0.04 & 0.04 & 0.05 \\
Public Body & 0.23 & 0.26 & 0.24 & 0.2 \\
Other & 0.01 & 0 & 0.03 & 0.04 \\
Type of contracts & & & & \\
Market & 0.21 & 0.14 & 0.25 & 0.26 \\
Subsidized & 0.79 & 0.86 & 0.75 & 0.74 \\
Location of the dwelling & & & & \\
Center & 0.3 & 0.22 & 0.9 & 0.89 \\
Semi-center & 0.33 & 0.35 & 0.07 & 0.09 \\
Suburb & 0.38 & 0.43 & 0.03 & 0.02 \\
Geographical Area & & & & \\
North-West & 0.34 & 0.3 & 0.32 & 0.32 \\
North-East & 0.16 & 0.26 & 0.17 & 0.18 \\
Center & 0.2 & 0.15 & 0.18 & 0.17 \\
South & 0.21 & 0.23 & 0.22 & 0.23 \\
Islands & 0.08 & 0.06 & 0.11 & 0.1 \\
One bathroom & & & 0.97 & 0.99 \\
More than one bathroom & 0.15 & 0.15 & & \\
Heating & 0.73 & 0.82 & 0.88 & 0.94 \\
Median duration of the contract & 11 & 9 & 11 & 8 \\
Surface (square meters) & 79.38 & 75.61 & 73.89 & 73.76 \\
Rents (monthly) (in $€$ ) & 227.02 & 332.53 & 229.86 & 340.24 \\
\hline Number of observations & 1583 & 1621 & 4059 & 3963 \\
\hline
\end{tabular}

Note: Our calculation from the SHIW and the HCS. Weighted statistics.

\subsubsection{Estimation results}

Estimation results (for brevity the first and last adjacent years available in the sample) are provided in Table 12. Both for HCS and SHIW data, our specification, weighted with sample weights, explains on average about $40 \%$ of the variation in rents.

As expected rents vary inversely with the duration of the contract, which gives evidence for a strong sitting tenant discount induced by Italian rent 
legislation. We use a continuous variable for duration to take account of the natural aging of the dwelling, and the fact that upon change of tenant, rented apartments generally undergo some maintenance work (painting, etc.).

Extra features, like the presence of an additional bathroom and heating, contribute, as expected, to an increase in rent. Unsurprisingly, dwellings owned by the private sector (either individuals or companies) are significantly more expensive than those owned by the public sector. Furthermore, apartments rented under market contracts are significantly more expensive than those leased with subsidized contracts ("equocanone" and the like). Rents are below average for houses located in non-central areas of the town, in particular those in the suburbs. As to geographical differentials, we find that rents in the South fall short of the level of those in the Center, with the gap increasing from 1998 to 2006. Average rents in the northern regions stand below those in the Center, probably because of the strong impact of the observations in Rome. For the SHIW sample, moving from a $50 \mathrm{~m}^{2}$ flat to a $75 \mathrm{~m}^{2}$ flat led to an increase in rents of $26 \%$ and 21\%, in 1998 and 2006 respectively, i.e. the premium for an additional square meter decreased over time probably because of the reduction in the average number of rooms. ${ }^{11}$

Comparing the SHIW with the HCS sample, some small differences between the parameter estimates relating to house characteristics emerge. On average, rents under market type contracts are higher than those under regulated contracts, although a smaller differential is estimated in the HCS sample. Flats including heating are more expensive in the SHIW sample than in the HCS one, with a non significant coefficient in 2006 for this variable.

As to the estimated price dynamics, we find that the implied hedonic price indices estimated from the SHIW and the HCS provide a similar picture over the reported sample, albeit some differences emerge from year to year. Figure 4 shows the implied hedonic price indices, the official CPI for rents and the national account rents deflator (CNA). The CNA index rose by more than $50 \%$ between 1998 and 2006, while the CPI increased by around $20 \%$. ${ }^{12}$ Interestingly, our hedonic based indices are almost in line with the CNA index, with an overall price increase of approximately $40 \%$ between 1998 and 2006. We believe that the difference might be due to the fact that the methodology underlying the CNA index fails to control for contract duration,

\footnotetext{
${ }^{11} \mathrm{~A}$ complete proof could not be provided given that number of rooms is not surveyed. We also tried a specification that includes $(\log (S))^{2}$, but the variable was not significative.

${ }^{12}$ As previously mentioned, a direct comparison is limited by the fact that these indices are calculated using different methodologies (see Section 3).
} 
which we find to be an important source of price variation.

Figure 4: Hedonic Price Indices and official indices for rents prices

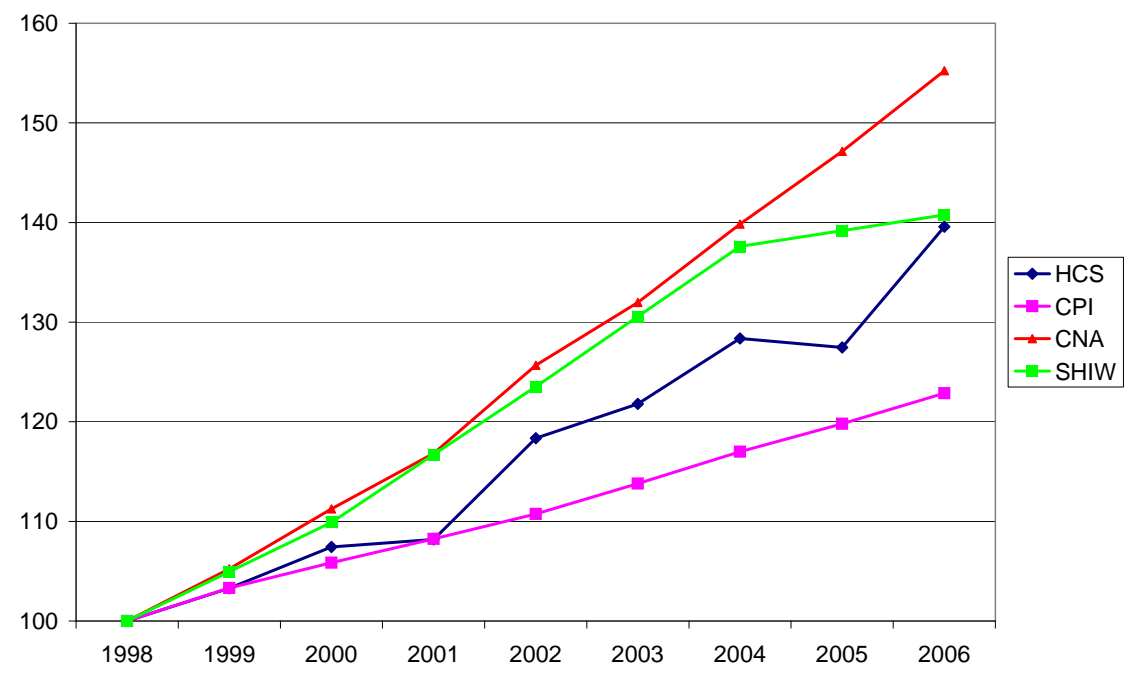

Notes: Hedonic estimates for the SHIW and the HCS are compared with official CPI and National Accounts data (CNA). Estimated equations are based on the regressors listed in Table 12.

Within the current framework we can also investigate whether rent dynamics display sizeable heterogeneity across segments of the population. To this end we estimate hedonic regressions on sub-samples of the SHIW dataset: more precisely we interact specific population groups with time dummies to derive the particular population index using both the time dimension and the interaction. ${ }^{13}$ We consider three dimensions of variation: age of the head of the household, income and type of rent contract. We find that in the period 1998-2006 wealthier households (defined as those with income in the upper quartile) experienced higher rent increases than lower income ones, with a gap of approximately $15 \%$ in the overall price increase (see appendix B, Figure 7 graph a). A smaller discrepancy in rent increases emerges between households where the head is older than 65 and those where he/she

\footnotetext{
${ }^{13}$ Similar results are obtained by allowing the entire hedonic relationship to adjust and calculating population-specific price indices from the estimated time dummies in each model.
} 
is younger than 30 years old (see Figure 7 graph b). This may be due to a selection effect, leading to a sorting out of young and lower income individuals from the rental market. Finally, market rents increased more than subsidized ones, albeit only starting from 2002 (see Figure 7 graph c).

\subsection{Matched models}

The statistical methodology used for the construction of rent dynamics is related to the nature of the survey used: while a rough measure of rent price is available from SHIW, HCS, CI, OMI and CPI (as they are all provided with a cross section dimension), the panel dimension could be exploited in the SHIW data set only. We will focuss on advantages and limitations of these approaches and discuss possible implications.

Unconditional rent measures and matched-type indices are presented in Sections 4.2 .1 and 4.2 .2 respectively.

\subsubsection{Unconditional dynamics}

According to the CPI data, between 1998 and 2006 Italian rents increased by $23 \%$ at an average annual rate of $2.6 \%$. In 2001 and 2002 the annual rate of growth of rents was particularly subdued at $2.3 \%$, peaking in 2003 at $2.8 \%$, as shown in Table 6 . Such a development is particularly striking when considering the very rapid pace of growth recorded from other sources on tenant rents.

Table 6: Unconditional rent dynamics (y-o-y growth rate)

\begin{tabular}{c|rrrrrrrrrr} 
& $\mathbf{1 9 9 8}$ & $\mathbf{1 9 9 9}$ & $\mathbf{2 0 0 0}$ & $\mathbf{2 0 0 1}$ & $\mathbf{2 0 0 2}$ & $\mathbf{2 0 0 3}$ & $\mathbf{2 0 0 4}$ & $\mathbf{2 0 0 5}$ & $\mathbf{2 0 0 6}$ & $\mathbf{2 0 0 7}$ \\
\hline CI & 3.8 & 13.8 & 7.2 & 1.9 & 10.1 & 6.0 & 4.7 & 12.2 & 4.3 & 2.6 \\
OMI & & & & & & & 8.0 & 6.9 & 6.1 & 3.6 \\
SHIW & 6.0 & 6.3 & 5.9 & 9.3 & 8.5 & 4.0 & 3.8 & 4.0 & 3.8 & \\
HCS & 5.4 & 0.1 & 1.6 & 5.9 & 11.3 & 3.4 & 5.5 & -0.6 & 13.2 & \\
CPI & 5.2 & 3.3 & 2.5 & 2.3 & 2.3 & 2.8 & 2.8 & 2.4 & 2.5 & 2.4 \\
\hline
\end{tabular}

Note: Price indices are calculated from average rents per square meter for SHIW and HCS. SHIW data in odd years are interpolated. OMI and CI data are already published per square meter. CPI figures are national rent indices. 
Using the SHIW surveys, between 1998 and 2006 rents increased by 56\%, at a rate of $7 \%$ a year (see Table 6). Unsurprisingly, average rents for households with market contracts in the SHIW rose much faster than those with subsidized contracts ( $68.2 \%$ and $50 \%$ respectively, mirroring the sharp rise in house prices in the same period. A similar picture is obtained by considering average rents from the HCS which, in the same period, increased by $47 \%$ (5.8\% per year). According to the HCS rents peaked after the introduction of the Euro in 2002 showing an increase of around $11 \%$ in year-on-year terms. ${ }^{14}$

It is interesting to note that sitting tenants obtain a significant discount compared to new ones: for instance, if we focus to the SHIW sample of households living in the same house and participating in more than one survey, their average rent per square meter is much lower (by about $15 \%$ in the years 2000-2006) than the one for the entire cross-section. ${ }^{15}$

Because of the nature of the HCS and SHIW surveys, measured rents are a mixture of existing, renewed and new rental contracts. Hence, it is not surprising to find that their annual increases are well below those recorded by the CI and the OMI surveys, which only consider new rent contracts (see Figure 5). Between 1998 and 2006 rents collected by the CI survey rose by almost $80 \%$, with an average annual growth of $7.5 \%$. However, the yearon-year increases are quite volatile, with some years displaying growth rates above 10\% (in 1999, 2002 and 2005). According to the OMI survey, in the years 2003-2007 (2002 was not considered as only the second half of the year is available) rents increased by around $27 \%$; in the same period CI rents increased by $25.8 \%$. However, their annual rates of increase in this period are quite different.

The price increase estimated from SHIW is approximately 10 percentage points above the one computed controlling for observed household characteristics discussed in the previous section.

\footnotetext{
${ }^{14}$ Average rents per square meter for the HCS survey have been computed imputing the size of the dwelling derived from the last General Census of Population and Housing available (2001). The imputation is based on variables common to both surveys: region and number of rooms.

${ }^{15}$ Both the HCS and the SHIW report the year of first residence in the dwelling: evidence of mis-reporting emerges in both surveys.
} 
Figure 5: Unconditional rent dynamics: $1998=100$

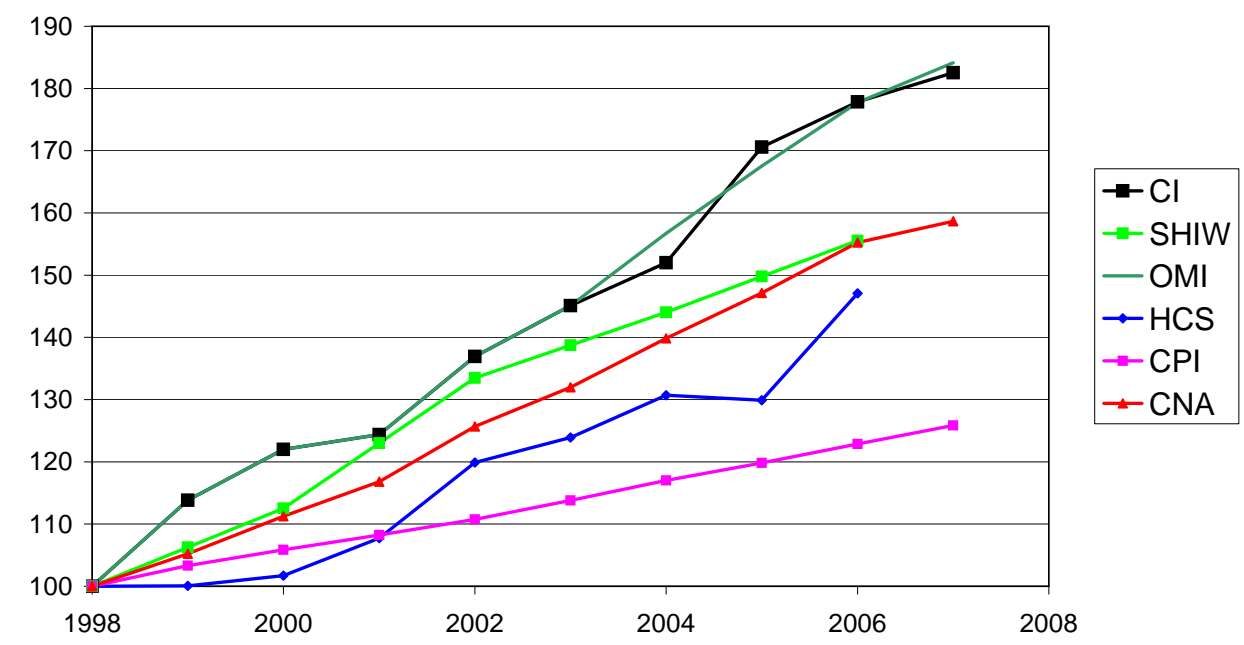

Note: OMI data are assumed to be equal to CI before 2002.

\subsubsection{Matched fixed base and chained price index}

The unconditional rent statistics presented in section 4.2.1 only provide a rough measure of rent price developments, as they are calculated on crosssectional data. Each year households with different demographics and different dwellings enter the sample, while others exit it. We hence explored the possibility of calculating alternative measures of rent price developments using the SHIW panel dimension. Unfortunately, a similar exercise is not feasible with the HCS as no household identifier is available to match units across years.

In theory two types of matched-model indices could be computed focusing on specific sub-samples of the households. In particular, fixed-base and chained-type indices could be obtained using households repeatedly sampled starting from the base-year, or only using data on households sampled across adjacent years.

Table 7 displays the SHIW transition matrix across survey years for the sub-sample of households renting a house. The matrix should be interpreted as follows: looking at the 1047 sampled households renting their house in 
Table 7: Tenant transition matrix for panel households

\begin{tabular}{|cccccc|}
\hline & \multicolumn{5}{c|}{ Sampled year } \\
First year in the panel & $\mathbf{1 9 9 8}$ & $\mathbf{2 0 0 0}$ & $\mathbf{2 0 0 2}$ & $\mathbf{2 0 0 4}$ & $\mathbf{2 0 0 6}$ \\
\hline$<=\mathbf{1 9 9 8}$ & 1596 & 655 & 394 & 270 & 195 \\
$\mathbf{2 0 0 0}$ & & 1047 & 217 & 124 & 83 \\
$\mathbf{2 0 0 2}$ & & & 1062 & 201 & 105 \\
$\mathbf{2 0 0 4}$ & & & & 1084 & 256 \\
$\mathbf{2 0 0 6}$ & & & & & 984 \\
Total & 1596 & 1702 & 1673 & 1679 & 1623 \\
\hline Share of panel renters & & .38 & .37 & .35 & .39 \\
\hline Share of panel households & .48 & .45 & .45 & .51 \\
\hline \hline
\end{tabular}

Souce: Our calculation from the SHIW. "Share of panel households" refers to the full SHIW sample

2000, 217 are still in the panel in 2002, 124 in 2004 and so on. As shown by the figures reported just above the main diagonal (i.e. the number of households interviewed across adjacent surveys) the panel attrition is substantial. The corresponding rent dynamics (in year-on-year) for the fixed-base matched model is reported in Table 8 , but the size of the sample considered makes it completely unreliable.

Table 8: Matched-model y-o-y growth rate

\begin{tabular}{|c|cc|cc|}
\cline { 2 - 5 } & \multicolumn{2}{|c|}{ Fixed-base matched models } & \multicolumn{2}{c|}{ Chained matched models } \\
\cline { 2 - 5 } $\mathbf{2 0 0 0}$ & Rent & N. Obs & Rent & N. Obs \\
\cline { 2 - 5 } $\mathbf{2 0 0 2}$ & 0.6 & 651 & 10.6 & 637 \\
$\mathbf{2 0 0 4}$ & 3.9 & 394 & 14.4 & 587 \\
$\mathbf{2 0 0 6}$ & 0.6 & 270 & 14.6 & 578 \\
\hline
\end{tabular}

Souce: Our calculation from the SHIW. Dutot Indices (ratio of the arithmetic mean of rents).

The problem of sample attrition can instead be partially tackled with a chained matched model, with price increases calculated considering only households sampled over adjacent surveys. The dynamics of the resulting index are more in line with those computed using unconditional averages 
in Section 4.2.1 as shown in Figure 6: between 1998 and 2006 rents of this particular set of households increased by $57.5 \%$, with a rise of almost $15 \%$ in 2002 alone.

In summary, over the period 1998-2006, the hedonic measure points to an average rent increase of approximately $40 \%$, in line with the dynamic of the national account rent deflator which rose by more than $50 \%$, and almost 20 percentage points above the one recorded by the "tenant rent" component of the CPI (see Table 9). Our estimates range between the national CPI for rents (lower bound) and the market based measures (CI and OMI). These findings are not surprisingly as the former inspects apartments holding fixed certain characteristics and the latter samples new rent contracts. ${ }^{16}$

Figure 6: Unconditional, fixed base and chained indices: $1998=100$

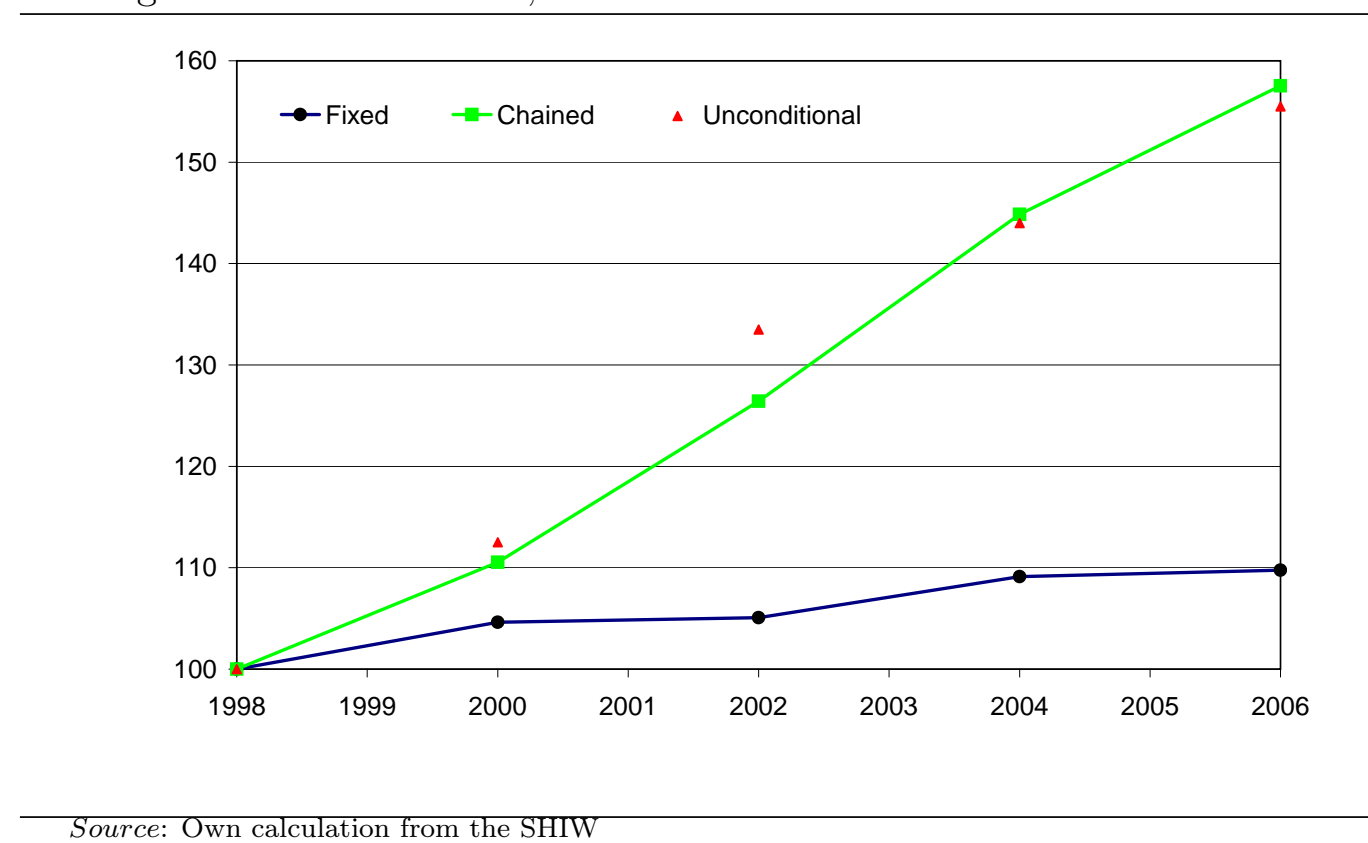

\footnotetext{
${ }^{16}$ To better gauge these divergences between different methods and data, we calibrate for the Italian context the model of CPI price collection introduced in Crone et al. (2006) attempting at quantifying the potential sources of underestimation of rents inflation in the US. We find that non response bias can only partially explain the gap between our estimates and the CPI based measure. Other factors may indeed play a role in attenuating further the price increases recorded by the official index with respect to our preferred measure obtained from the hedonic regressions. A full assessment of the model is beyond the scope of the paper and is the object of future research (Rondinelli and Veronese, 2010.)
} 


\section{Table 9: Cumulated rent increase (1998-2006)}

(percentage points)

\begin{tabular}{ll|cccccc}
\cline { 3 - 7 } & & CPI & CNA & SHIW & HCS & CI & OMI \\
\hline Official data & 23 & 55 & & & & \\
Unconditional dynamic & & & 56 & 47 & 78 & 78 \\
Hedonic Methods & & & 41 & 40 & & \\
Matched Models: & & & & & & \\
& & & & 10 & & & \\
& Fixed Base & & & 58 & & & \\
\hline
\end{tabular}

Notes: Our calculation from various sources and methods. CPI: consumer price Index, rent component (ISTAT); CNA: national account rent deflator (ISTAT); SHIW: survey of Italian household income and wealth (Bank of Italy); HCS: household consumption expenditure budget survey (ISTAT); CI: Consulente Immobiliare; OMI: Osservatorio del Mercato Immobiliare (Agenzia del territorio). Official data for CPI and CNA rent index.

\section{Conclusions}

This paper explores various statistical approaches to the construction of rent indices and evaluates their dynamics over the years 1998-2006. This was also a period during which house prices increased by $60 \%$, which in principle should also affect rent evolution. Exploiting five publicly available data sources we compile rent indices from unconditional and matched-models and hedonic methods. Our estimates suggest substantial differences in rent dynamics according to the various sources and methods.

The hedonic analysis reveals that the contract duration is an important source of heterogeneity of prices, with rents for sitting tenants well below those for new tenants. Given the lengthy duration of contracts common to Italy, average rents are expected to incorporate the changes recorded by new contracts, which are closely related to the house price dynamics, only very slowly. A substantial part of rent increase takes place when the tenant moves: within the duration of a contract, rent contract are updated according to a specific indexation rule to the overall inflation. The owner is then free of setting a new price only when the contract expires which at that stage will also reflect house price dynamics. In the end, rent developments are also strongly affected by the turnover rate. In principle, price changes of the new 
contracts are what matters most for mobility choices. Reliable information on new rent contracts is however missing for Italy. We construct national rent indices aggregating the micro data information contained in the OMI and the CI surveys. We also investigate whether rent dynamics display sizeable heterogeneity across various segments of the population. To this end we estimate hedonic regressions on specific sub-samples of the SHIW population. Even after controlling for quality, non subsidized rents rose much faster than those subject to some regulation. Furthermore, while we find that younger and lower income households are more likely to rent their residence, we do not find evidence of stronger price increases affecting these sub-groups. On the contrary, over the period 1998-2006, price dynamics were stronger for higher income and older families. This may arise from a selection effect, leading to a sorting out of young and lower income individuals from the rental market. An empirical assessment of this conjecture is beyond the scope of the current paper.

As to the measurement issue, according to our calculations, over the period 1998-2006, tenant rents increased substantially, with estimates ranging between 40 and $80 \%$. This wide variation is not surprisingly as we are comparing indices constructed with different methodologies and where the underlying samples are obtained from surveys with alternative purposes. The upper bound of these estimates refers to measures relying on data from new rent listings, which presumably reflect the changing composition of vacant apartments on the market. The hedonic approach applied to household surveys suggests instead a substantially lower overall growth in tenant rents, around $40 \%$ for the same period.

These estimates are not at odds with some of the official measures published by ISTAT. In particular, between 1998 and 2006 the national account rent deflator rose by more than $50 \%$ in line with the rent dynamic estimated from SHIW and HCS. In contrast, the increase of the "tenant rents" component of the CPI amounted to 20\%, substantially lower than both our most conservative calculations and the national account rent deflator. 


\section{A Contractual arrangements for rents}

The house rental market in Italy was strictly regulated until the beginning of the 1990s, with price indexation schemes and pre-determined contractual arrangements which strongly protected tenants. The so called "equo-canone" law (L.392/78) imposed a strict rent-control mechanism, automatic renewals and city/area price caps to rents. Furthermore, contracts were generally of long duration because it was extremely difficult for the landlord to evict a tenant. A progressive deregulation of the rental market started in 1992 (L.359/1992), with the introduction of the so called "patti in deroga" contracts, allowing some elements of flexibility in the relation between landlord and tenant. The deregulation was further extended in 1998 with a new legislation on the rental market (L. 431/98), establishing four types of contracts: a) unregulated contracts (known as "completamente liberi") in which both tenant and landlord are free to choose the amount of the rent to be paid and the duration of the contract, b) semi-regulated rent (known as "canoni concordati") in which the rent and the contract duration are subject to a binding regulation, c) short-term leases and student housing contracts, ${ }^{17} \mathrm{~d}$ ) short term contracts (3 months or longer) for students and transient workers.

The most common unregulated contract is set for four years and can be renewed for an additional four years if the tenant and the landlord agree on the contract conditions. If a landlord needs to claim a property before the contract expires, he/she can do so by giving the tenant written notice six months in advance. Termination of the contract is allowed only under specific conditions (i.e. the owner's decision to live in the house, or the need to make major renovations and repairs before selling it). ${ }^{18}$ When the contract expires, the landlord may claim back the property giving notice six months in advance.

Semiregulated contracts are for a period of three years with the option of renewal for two more years. Both the rent and the contract duration are established at the city level by commissions composed of representatives from the municipality, trade unions and the landlords' association. These contracts are available to landlords and tenants in most Italian towns.

\footnotetext{
${ }^{17}$ Some "equo-canone" contracts are still in place, especially in publicly owned properties, but their share is declining.

${ }^{18}$ However, if within one year, the property is not used for the purpose stated in the notification, the landlord must renew the contract with the original tenant or pay an amount equal to three years' rent as compensation.
} 


\section{B Additional tables and figures}

\section{Table 10: Survey variable description}

\begin{tabular}{|c|c|c|c|c|c|}
\hline & SHIW & Census & HCS & OMI & CI \\
\hline Rent amount & $\mathrm{X}$ & & $\mathrm{X}$ & $\mathrm{X}$ & $\mathrm{X}$ \\
\hline Rent level in 2006 (in $€$ ) & 333 & & 340 & 523 & 635 \\
\hline \multicolumn{6}{|l|}{ Principal residence by tenure } \\
\hline Owned & $\mathrm{X}$ & $\mathrm{X}$ & $\mathrm{X}$ & $\mathrm{X}$ & $\mathrm{X}$ \\
\hline Rented & $\mathrm{X}$ & $\mathrm{X}$ & $\mathrm{X}$ & $\mathrm{X}$ & $\mathrm{X}$ \\
\hline \multicolumn{6}{|l|}{ Type of contract } \\
\hline Market & $\mathrm{X}$ & & $\mathrm{X}$ & $\mathrm{X}$ & $\mathrm{X}$ \\
\hline No Market & $\mathrm{X}$ & & $\mathrm{X}$ & & $\mathrm{X}$ \\
\hline House ownership & $\mathrm{X}$ & $\mathrm{X}$ & $\mathrm{X}$ & & \\
\hline Location of the dwelling & $\mathrm{X}$ & & $\mathrm{X}$ & $\mathrm{X}$ & $\mathrm{X}$ \\
\hline Dwelling type & $\mathrm{X}$ & & & $\mathrm{X}$ & \\
\hline Neighbors' status & & & $\mathrm{X}$ & & \\
\hline Size of the dwelling & $\mathrm{X}$ & $\mathrm{X}$ & & & \\
\hline Maximum detailed geographical area & town & region & region & micro-zones & 3 town area \\
\hline Sampled units & households & houses & households & houses & houses \\
\hline Average number per wave & 8,000 & $1 \%$ sample & 23,500 & 181,000 & 103 \\
\hline Availability of the Survey & $1964-2006$ & $1981-2001$ & $1995-2006$ & $2002-2007$ & $1984-2007$ \\
\hline Frequency of the Survey & 2 years & 10 years & annual & 6 months & 6 months \\
\hline
\end{tabular}

Notes: SHIW=Survey of Italian Households Income and Wealth (Bank of Italy); Census=1\% random sample from ISTAT General Census of Population and Housing; HCS=ISTAT Household Consumption Survey; OMI=Osservatorio Immobiliare (Agenzia del Territorio); CI=Consulente Immobiliare. Rent level in 2006 for OMI and CI are calculated for an average house of $75 \mathrm{~m}^{2}$. Market contract includes "patti in deroga" and "uso foresteria" while no-market contract "equocanone", "contratti popolari", "contratti sociali". House ownership refers to the person that owns the household dwelling (parents, children, other relatives, private companies, IACP, etc..); Dwelling type relates to the type of house/flat (luxury, upscale, mid-range, etc..). 


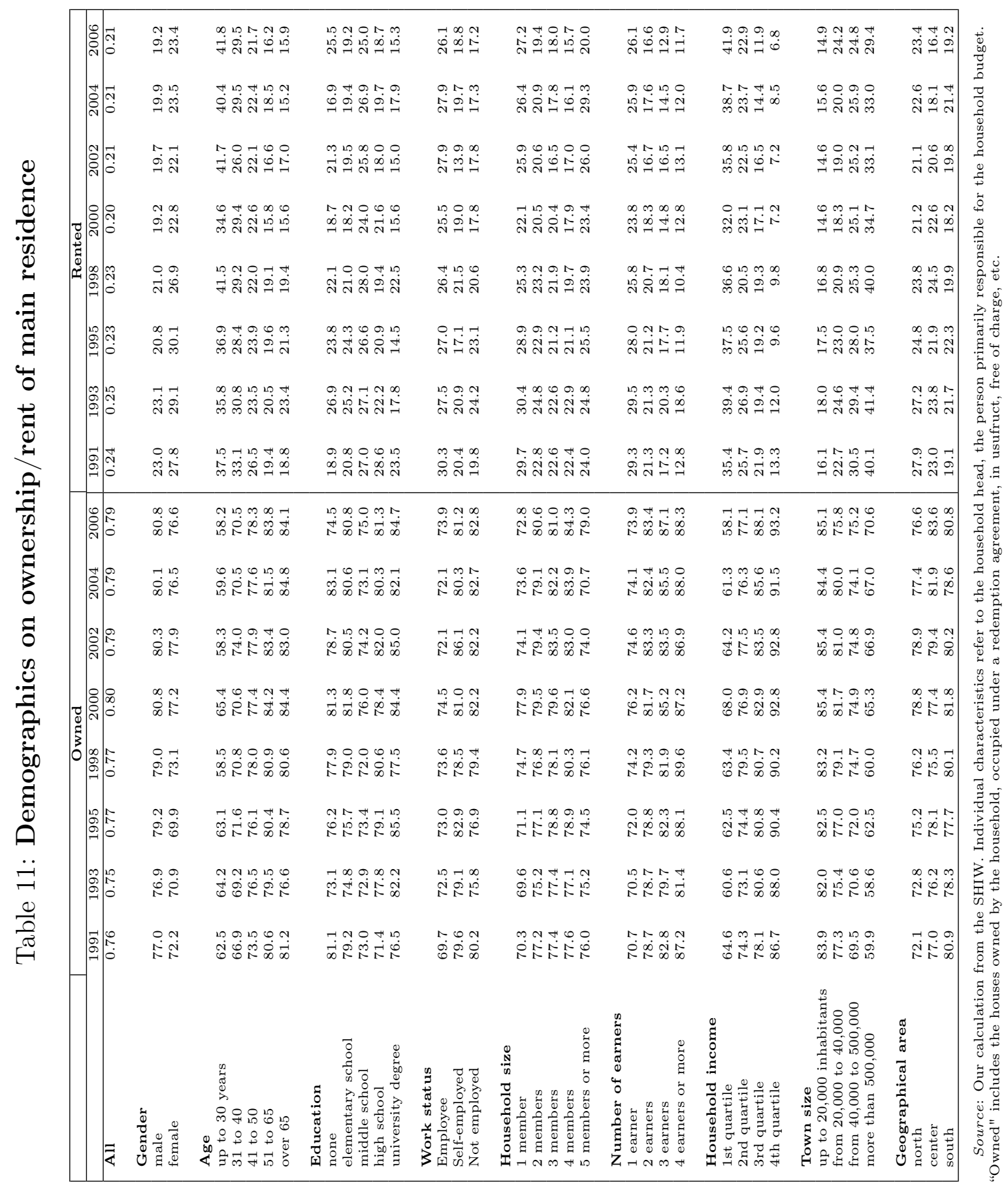




\section{Table 12: Adjacent year hedonic regression: the SHIW and the HCS}

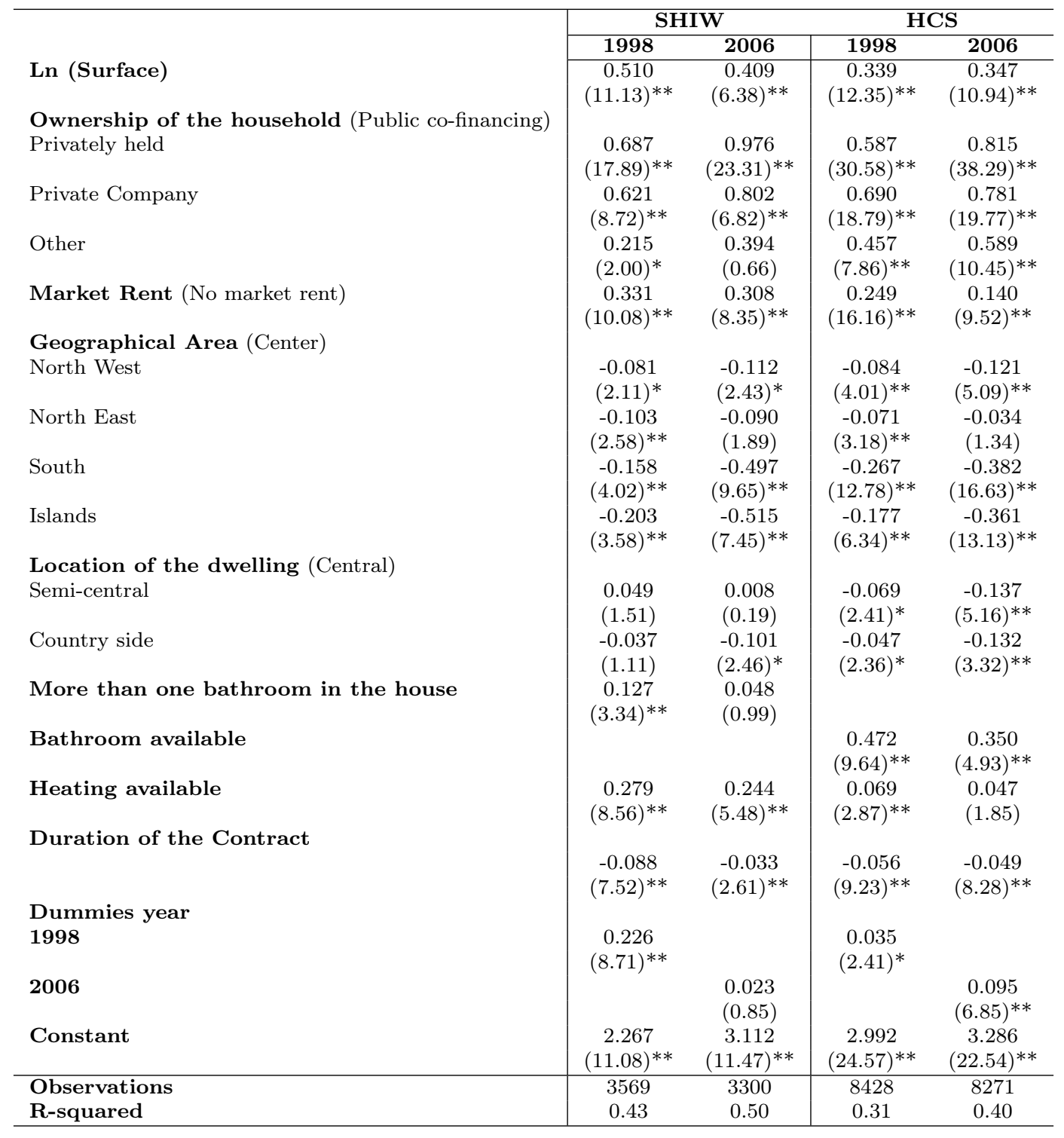

Source: Our calculation from the SHIW and the HCS. Individual characteristics refer to the head of the household, the person primarily responsible for the household budget. Duration of the contract is a continuous variable.

Robust $\mathrm{t}$ statistics in parentheses. * significant at $5 \%$; ** significant at $1 \%$. 
Figure 7: The hedonic rent index by:

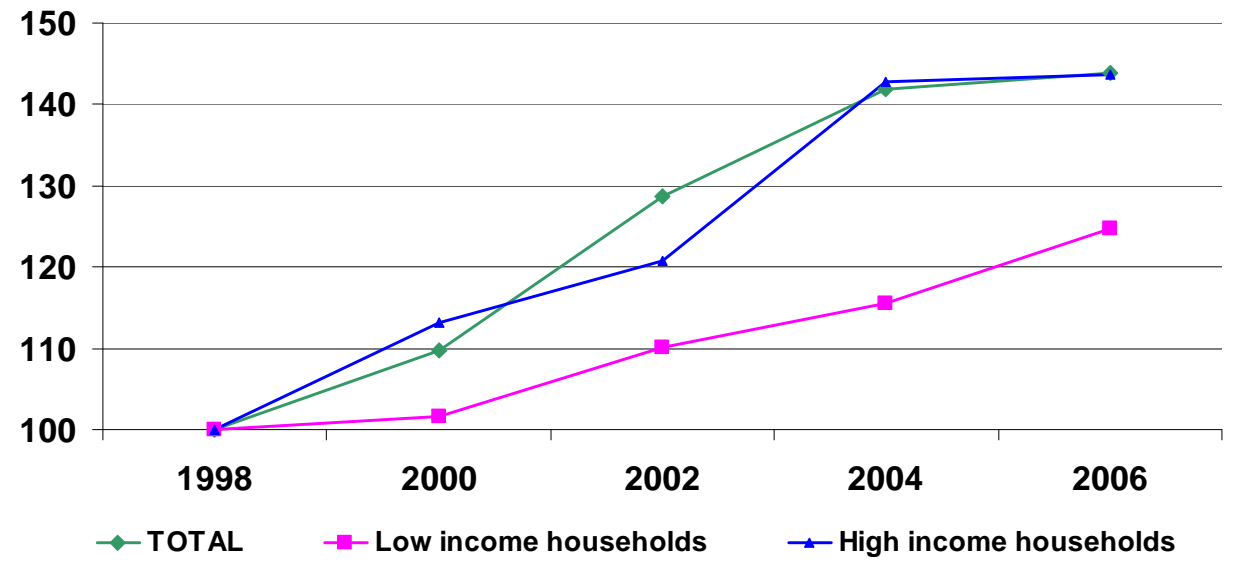

(a) Household income

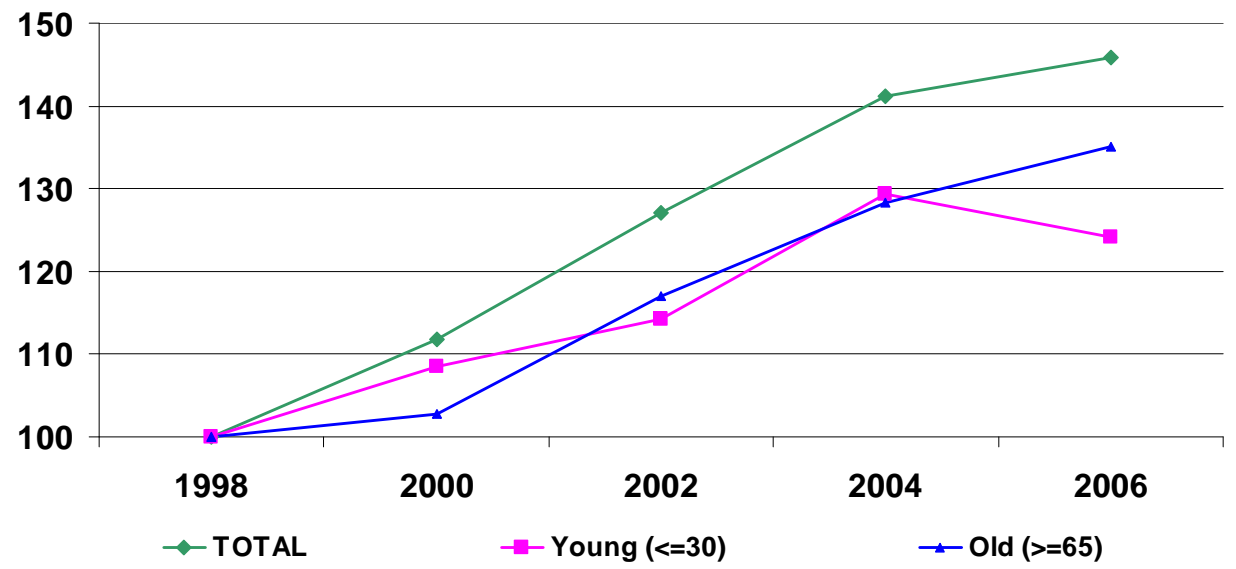

(b) Household age

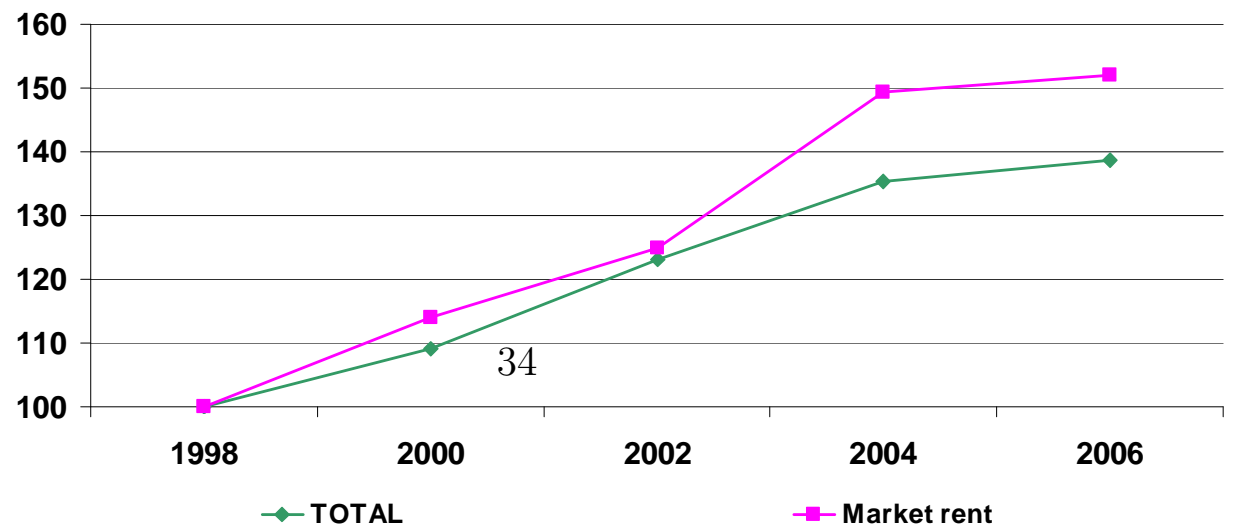

(c) Typology of the contract

Notes: Our calculation from the SHIW. Estimated equation based on the regressors listed in Table 


\section{References}

Becker S.O., Bentolila S., Fernandes A., Ichino A. (2005) Youth emancipation and perceived job insecurity of parents and children, IZA Discussion Papers 1836, Institute for the Study of Labor (IZA).

Bentolila S., Dolado J.J. (1991) Mismatch and internal migration in Spain, 1962-1986, in: Mismatch and Labour Mobility, Padoa Schioppa F., ed., Cambridge University Press, New York, 182-234.

Boeri T., Brandolini A. (2005) The age of discontent: Italian households at the beginning of the decade, IZA Discussion Papers 1530, Institute for the Study of Labor (IZA).

Cannari L., Faiella I. (2008) House prices and housing wealth in Italy, in: Household Wealth in Italy, Banca d'Italia (ed.), Rome, 91-110.

Cannari L., Nucci F., Sestito P. (1997) Mobilità del lavoro e mercato immobiliare: un'analisi empirica per l'Italia, Rivista Italiana degli Economisti.

Cresme (2005) Rapporto sulla questione abitativa e il mercato della casa in Italia, Technical report.

Crone T.M., Nakamura L.I., Voith R. (2006) The cpi for rents: a case of understated inflation, Working Papers 06-7, Federal Reserve Bank of Philadelphia.

Duce Tello R. (1995) Un modelo de elección de tenencia de vivienda para Espana, Moneda y Crédito, 201, 127-152.

Ermisch J. (1999) Prices, parents, and young people's household formation, Journal of Urban Economics, 45, 1, 47-71.

Gambacorta R., D'Alessio G. (2007) Home affordability in Italy, Questioni di Economia e Finanza 9, Banca d'Italia.

Goodhart C. (2005) Beyond current policy frameworks, Working Papers 189, BIS.

Gordon R.J., vanGoethem T. (2005) A century of housing shelter prices: Is there a downward bias in the cpi?, NBER Working Papers 11776, National Bureau of Economic Research, Inc. 
Griliches Z. (1971) Price Indexes and Quality Change: Studies in New Methods of Measurement, Harvard University Press.

Haurin D.R., Hendershott P.H., Kim D. (1993) The impact of real rents and wages on household formation, The Review of Economics and Statistics, $75,2,284-93$.

Hoffmann J., Kurz C. (2002) Rent indices for housing in West Germany 1985 to 1998, Working Paper Series 116, European Central Bank.

Kohler H., Billari F.C., Ortega J.A. (2002) The emergence of Lowest-Low fertility in Europe during the 1990s, Population and Development Review, $28,4,641-680$.

Muzzicato S., Sabbatini R., Zollino F. (2008) Prices of residential property in Italy: constructing a new indicator, Questioni di Economia e Finanza 17, Banca d'Italia.

Pakes A. (2003) A reconsideration of hedonic price indices with an application to PC's, American Economic Review, 93, 5, 1578-1614.

Pakes A. (2005) Hedonics and the consumer price index, forthcoming in Les Annales d'Economie et de Statistique.

Panetta F., Sabbatini R., Zollino F., Bianchi M., Bofondi M., Borselli F., Bulligan G., Buoncompagni A., Cappabianca M., Carpinelli L., Chiabrera A., Columba F., de Blasio G., D'Ignazio A., Fabrizi C., Gola C., Signoretti F.M. (2009) The performance of the Italian housing market and its effects on the financial system, Questioni di Economia e Finanza 59, Banca d'Italia.

Reis H.J., Santos Silva J. (2006) Hedonic prices indexes for new passenger cars in Portugal (1997-2001), Economic Modelling, 23, 6, 890-908.

Rondinelli C., Veronese G.F. (2010) A model of non response bias for the Italian CPI for rents, mimeo.

Osservatorio regionale sulla condizione abitativa (2008) La domanda abitativa in Lombardia, Technical report. 
Triplett J. (2004) Handbook on hedonic indexes and quality adjustments in price indexes: Special application to information technology products, OECD Science, Technology and Industry Working Papers 2004/9, OECD, Directorate for Science, Technology and Industry. 